Presented at the Fifth Annual 1993 International Symposium on Super Collider (IJSSC) in San Francisco, California, May 6-8, 1993

\title{
CORRECTOR/QUADRUPOLE/SEXTUPOLE POWER LEADS FOR THE RELATIVISTIC HEAVY ION COLLIDER AT BROOKHAVEN NATIONAL LABORATORY ${ }^{1}$
}

\author{
R. Shutt, K. Hornik, M. Rehak \\ RHIC Department \\ Magnet Division \\ Brookhaven National Laboratory \\ Upton, NY 11973
}

\section{INTRODUCTION}

In RHIC (Relativistic Heavy Ion Collider), there are 492 CQS (Corrector/Quadrupole/Sextupole) assemblies which require leads to carry the current from the power supply to the magnet. The lead assemblies will contain these leads along with instrumentation voltage taps and current carrying wires that are used only for magnet warm-up. These lead assemblies are analyzed for two cooling schemes: 1) gas flow through the lead tube and 2) heat sinking the lead tube along a 40-70 $\mathrm{K}$ heat shield (without gas flow). The analysis was extended to include the modeling of the cold and warm ends and effects of superinsulation shielding the lead assembly against radiation (including heat conduction due to residual gas pressure in the surrounding vacuum). Extensive parametric studies of heat exchange areas, specific copper properties, length of the lead, etc. are also included in the analysis.

\section{HEAT SINK vS. HELIUM FLOW}

An initial fixed end temperature analysis (cold end set to $4.4 \mathrm{~K}$, warm end set to $293 \mathrm{~K}$ ) was performed on the lead assembly for both the heat sinking and helium flow cooling schemes. The heat sink temperature was set at $50 \mathrm{~K}$ for this initial comparison. The optimal design should have a minimal heat load on the refrigeration system. This means for the gas flow case, the heat leak at the cold end $\left(\mathrm{Q}_{\mathrm{in}}\right)$ should be minimized while the mass flow is also minimized. This is represented by

$$
Q_{\text {tot }}=Q_{i n}+80 \times M
$$

where 80 is a factor used to translate helium mass flow into heat load on the refrigerator. For the heat sink case, it is necessary to minimize $Q_{\text {in }}$ while minimizing the length of the attachment to the shield in order to reduce the load on the refrigerator. Results of the heat sink analysis with the shield temperature set at $50 \mathrm{~K}$ show that the heat leak at the cold end is close to, and

'Work performed under Contract No. DE-AC02-76CH00016 with the U.S. Department of Energy

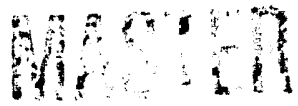


in some cases, exceeds the total refrigeration load of the gas flow case. The lead would have to be very long, on the order of 5 or 6 meters, for this type of lead to be considered. When the shield temperature is set to $60 \mathrm{~K}$, the performance is further reduced, and the refrigeration load on the heat shield is increased. Due to the performance indicated by the computer analysis, the difficulties presented with the installation of a 5 or 6 meter long lead, and uncertainty in the precision of the thermal contact that could be achieved between the lead tube and the heat shield, gas flow cooling was chosen.

\section{HELIUM FLOW- FINAL DESIGN}

The wires in this lead are such that two carry $100 \mathrm{~A}$ each and eight carry $50 \mathrm{~A}$ each. An analysis with end temperatures fixed at $4.4 \mathrm{~K}$ and $293 \mathrm{~K}$ was performed to determine an optimal length within a range that could reasonably fit within the CQS cryostat. According to Table 1, the optimal length would be $110 \mathrm{~cm}$. However, a final lead length of $90 \mathrm{~cm}$ was chosen, based on these results and physical restrictions on length due to space considerations. The lead should be long enough for the heat leak $\left(Q_{i n}\right)$ to be a minimal value, but short enough to fit inside the CQS cryostat assembly.

Table 1: Fixed end temperature analysis of CQS lead (4.4K at cold end, $293 \mathrm{~K}$ at warm end)

\begin{tabular}{cccc} 
Length of Lead,cm & $\mathrm{M}_{\text {crit, }}, \mathrm{g} / \mathrm{s}$ & $\mathrm{Q}_{\text {in }}, \mathrm{W}$ & $\mathrm{Q}_{\text {Lor }}, \mathrm{W}$ \\
\hline 80 & 0.033 & 1.00 & 3.65 \\
90 & 0.034 & 0.60 & 3.32 \\
100 & 0.034 & 0.48 & 3.20 \\
110 & 0.035 & 0.31 & 3.11 \\
120 & 0.036 & 0.25 & 3.13 \\
\hline
\end{tabular}

With the length of the lead determined, the end conditions were modeled to see the performance of the complete set-up. The $90 \mathrm{~cm}$ length refers to the length of wire enclosed in stainless steel flexible tube of $1.905 \mathrm{~cm}$ diameter. At the cold end, a length of wire extends past the end of the flexible tube containing the lead assembly into a large interconnect volume filled with helium. The lead wires are attached to superconducting wires in this volume. The interconnect region is modeled as an infinite volume of helium at $4.4 \mathrm{~K}$ that freely convects the heat from the copper wires. The helium gas flow in the flexible tube is modeled as forced convection of helium which removes the heat from the wires. At the warm end, the wires go through an expander and T-joint, where the helium leaves. The copper wires are then spliced to larger copper pieces that are insulated to separate the electric current from ground. Finally, the current passes through large cables that are attached to the power supply. These cables and the insulated copper pieces are exposed to free convection of air. Figure 1 is a schematic of the gas flow case.

\section{RESULTS}

Studies were made to determine the effects of material properties, heat exchange area, and sensitivity to exact lengths of each of the sections. Table 2 shows the effect of material properties on lead performance. This shows a great sensitivity of lead performance to the material used, particularly to the relative resistivity ratio, $R R R$. $Q_{\text {in }}$ could be minimized with a very impure copper, but the mass flow would be very high. The mass flow could be minimized with a very pure copper, but $Q_{\text {in }}$ would be very high. In most cases, $Q_{10 x}$ should be minimized. This is possible over a range of RRR. For this particular case, the RRR should not exceed 120 , but cannot be less than 80 due to mass flow constraints on this lead. 


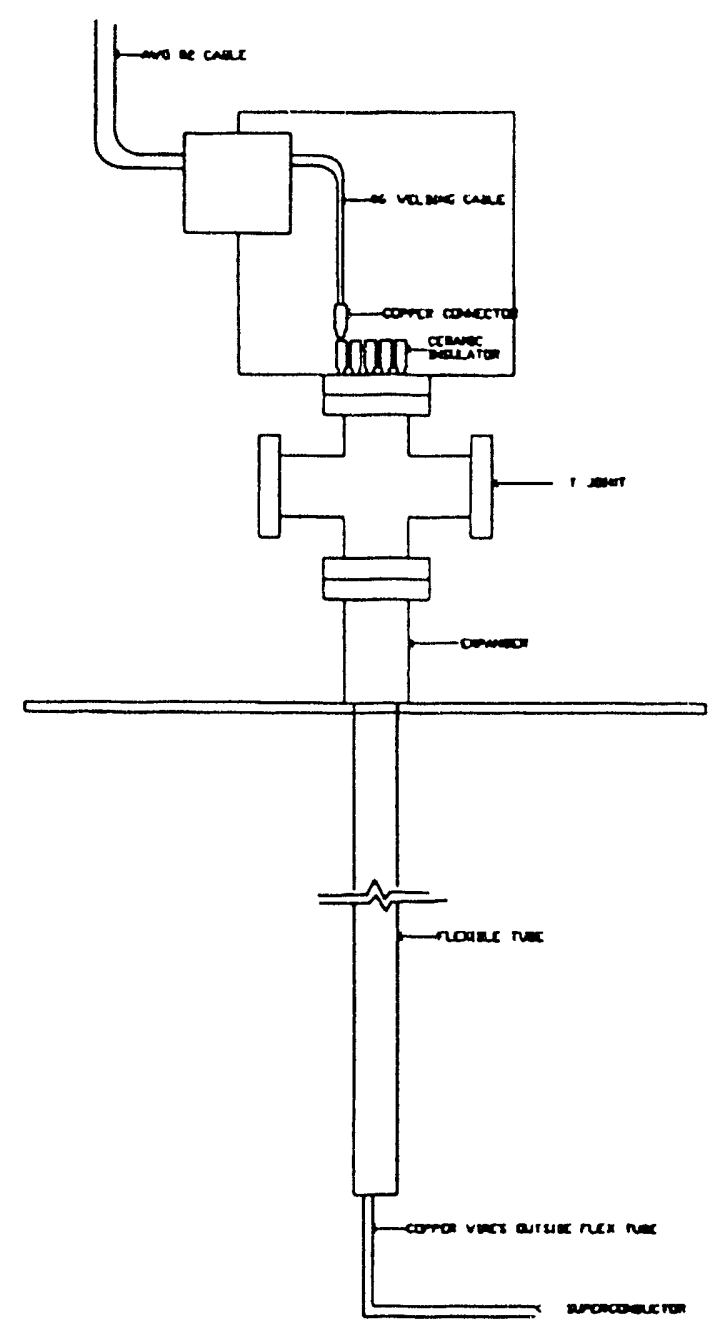

Figure 1. CQS gas flow assembly schematic.

Table 2: Material property study. All results for lead with end conditions included, $M=0.036$ $\mathrm{g} / \mathrm{s}$. $Q_{\text {lead }}$ is the heat leak into the interconnect volume, $T_{b c}$ is the helium temperature, $T_{1}$ is the temperature of the $100 \mathrm{~A}$ wires, $T_{2}$ is the temperature of the $50 \mathrm{~A}$ wires. All temperatures are at the warm end of the flexible tube.

\begin{tabular}{lllllll}
\hline Material & $\mathrm{Q}_{\text {in }}, \mathrm{W}$ & $\mathrm{Q}_{\text {lead }}, \mathrm{W}$ & $\mathrm{Q}_{\text {lod }}, \mathrm{W}$ & $\mathrm{T}_{\text {he }}, \mathrm{K}$ & $\mathrm{T}_{1}, \mathrm{~K}$ & $\mathrm{~T}_{2}, \mathrm{~K}$ \\
\hline ETP (RRR =100) & 0.08 & 1.00 & 2.96 & 213 & 290 & 236 \\
OFHC (RRR=106) & 0.04 & 0.56 & 2.92 & 230 & 304 & 251 \\
RRR =80 & 0.22 & 2.27 & 3.10 & 225 & 301 & 247 \\
RRR =120 & 0.41 & 2.80 & 3.29 & 202 & 280 & 227 \\
RRR =200 & 0.85 & 3.72 & 3.75 & 182 & 262 & 210 \\
\hline
\end{tabular}

A concern in this lead design is the amount of the wire that will actually be exposed to the flowing helium. The wires, when the lead is asse $n$ bled, are twisted together. Therefore, the entire perimeter is not exposed to cooling helium. Table 3 shows the results as the percentage of the perimeter exposed to flowing helium is varied. The less exposure to flowing helium, the warmer the copper becomes. For this model, a conservative estimate of $75 \%$ is applied. 
Table 3: Study of percentage of wire perimeter exposed to helium flow. All run at $0.036 \mathrm{~g} / \mathrm{s}$ with ETP as the material.

\begin{tabular}{lllllll}
\hline \% area & $\mathrm{Q}_{\text {in }}, \mathrm{W}$ & $\mathrm{Q}_{\text {lesd }}, \mathrm{W}$ & $\mathrm{Q}_{\text {lod }}, \mathrm{W}$ & $\mathrm{T}_{\text {hc }}, \mathrm{K}$ & $\mathrm{T}_{1}, \mathrm{~K}$ & $\mathrm{~T}_{2}, \mathrm{~K}$ \\
\hline 100 & 0.05 & 0.63 & 2.93 & 194 & 244 & 212 \\
90 & 0.06 & 0.73 & 2.94 & 198 & 257 & 218 \\
80 & 0.07 & 0.89 & 2.95 & 206 & 276 & 228 \\
75 & 0.08 & 1.00 & 2.96 & 213 & 290 & 236 \\
70 & 0.09 & 1.15 & 2.97 & 224 & 308 & 247 \\
\hline
\end{tabular}

A study to determine the number of layers of superinsulation needed to keep the effects of radiation on lead performance at a minimum was made. The worst case for radiation would occur if the inside surface of the vacuum chamber were at $293 \mathrm{~K}$. Heat would be radiating into the lcad tube along the entire length. With one layer of superinsulation, $Q_{\text {lead }}$ is $1.7 \mathrm{~W}$. After fifteen layers, $\mathrm{Q}_{\text {lead }}$ remains constant at $1.0 \mathrm{~W}$. If the lead was placed in an environment where radiation was not a factor, $\mathrm{Q}_{\text {lead }}=0.99 \mathrm{~W}$. Therefore, it is shown that at least 15 layers of insulation are necessary to keep the effects of radiation on lead performance at a minimum.

A sensitivity study was done in which the length of each section of the lead was varied individually to see the effect on the end lead temperature. The results of these analyses were evaluated and a worst case for burn-out and a worst case for freezing were chosen. Burn-out is defined as the point where the temperature of the lead reaches $450 \mathrm{~K}$. The worst case for freezing would indicate the temperature of the helium and stainless steel tube at the exit of the vacuum chamber and give an idea of the likelihood of condensation or frost forming on the outside of the stainless steel. An analysis where the ends of the leads are fixed at $4.4 \mathrm{~K}$ and 293 $\mathrm{K}$ does not indicate the presence of condensation on these assemblies. The actual model of the end conditions must be included for this situation to become apparent. Table 4 compares the two worst cases to the proposed design. If the worst case for burnout was actually built, the temperature would still not reach $450 \mathrm{~K}$.

Table 4: Proposed case, worst cases for both freezing and burn-out. All run at $\mathrm{M}=0.036 \mathrm{~g} / \mathrm{s}$

\begin{tabular}{llllll}
\hline case & $\mathrm{Q}_{\text {in }}, \mathrm{W}$ & $\mathrm{Q}_{\text {lead }}, \mathrm{W}$ & $\mathrm{T}_{\text {he }}, \mathrm{K}$ & $\mathrm{T}_{1}, \mathrm{~K}$ & $\mathrm{~T}_{2}, \mathrm{~K}$ \\
\hline proposed & 0.08 & 1.00 & 213 & 290 & 236 \\
worst/burn & 0.01 & 0.51 & 265 & 348 & 283 \\
worst/freeze & 1.61 & 4.03 & 180 & 249 & 213 \\
\hline
\end{tabular}

\section{CONCLUSIONS}

In order to get an accurate picture of lead performance, the entire lead, including specific end conditions, must be modeled. An analysis where the ends are arbitrarily fixed at $4.4 \mathrm{~K}$ and $293 \mathrm{~K}$ does not indicate the presence of condensation, nor does it indicate the true temperatuie of the lead as it exits the cryostat. The lead does not end where the helium exits the system. The surrounding equipment must also be modeled in order to find the true temperature of the lead.

The model shows that different RRR and types of coppers can behave very differently. This is an important factor in determining the heat load on the refrigerator and how the heat is dissipated. 


\section{DISCLATMER}

This report was prepared as an account of work sponsored by an agency of the United States Goverament. Neither the United Stutes Goverment nor any agency thereof. aor any of their exployees, mikes any warranty, expres or implied, or nerumes any legal linbility or responsibitity for the acearacy, compieteness, or usefulness of any information, apparzens, produch or process disclosed ar represents that its use would not infringe privarely owned rights Reference herein to any specinic commervial produce, process, or service by trade mme, tridemarte manufac-

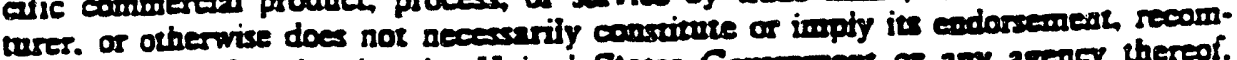
mendation. or favoring by the United States Goverment or any apency thereof. The views and opinions of auchors expresed herien do not necencarily state or reflect those of the United States Govermment or any afeecy therwot. 

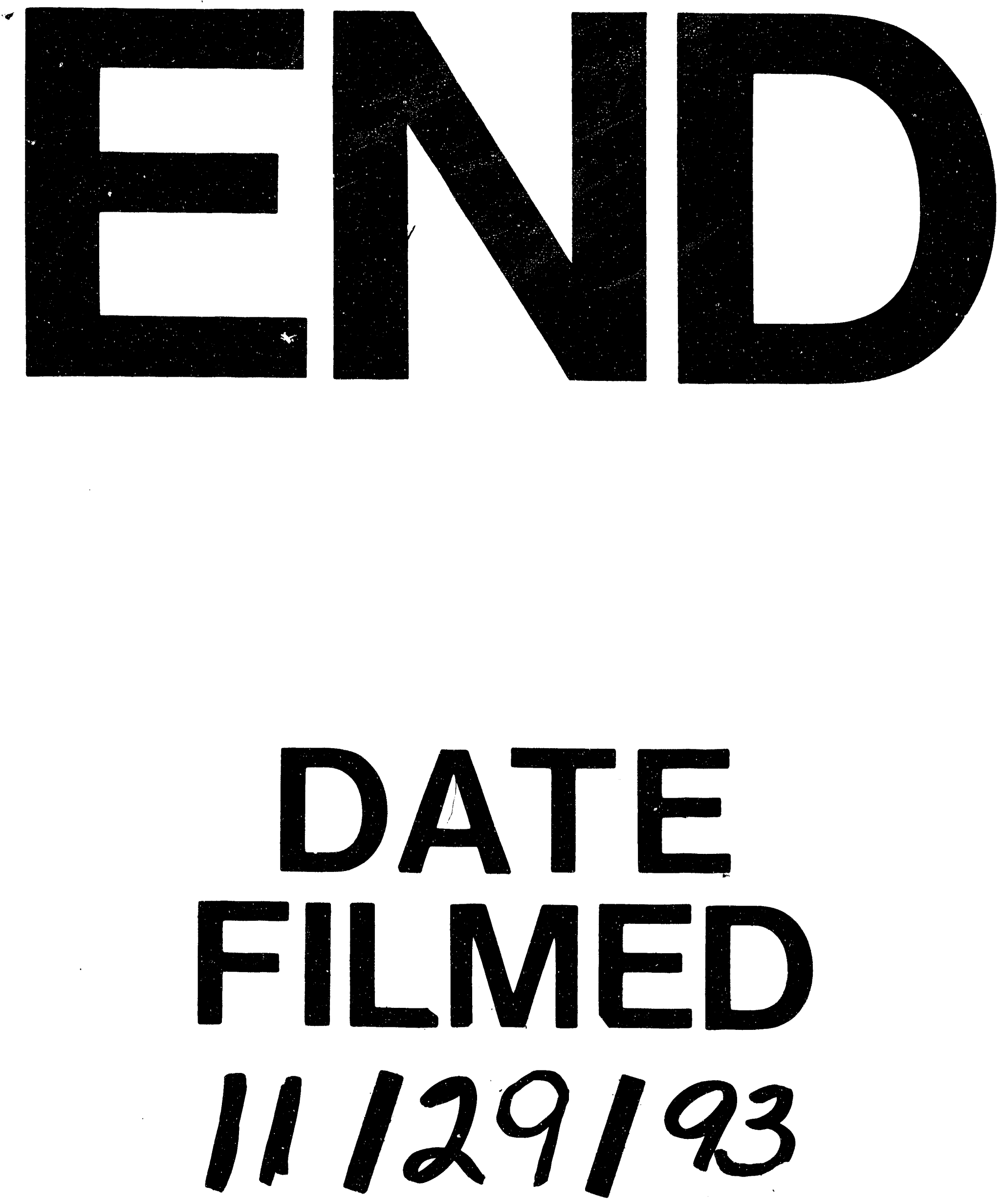
